\title{
Problems of using pumped storage power plants to improve the reliability and controllability of electric power system of the republic of Uzbekistan
}

\author{
Murodilla Mukhammadiev ${ }^{1, *}$, Boborakhim Urishev ${ }^{2}$, Shirin Esemuratova ${ }^{1}$, and Nigina Djumaniyozova ${ }^{1}$ \\ ${ }^{1}$ Tashkent state technical university, 2 Universitet street Tashkent, Uzbekistan \\ ${ }^{2}$ Karshi engineering institute, 225 Mustaqillik street Karshi, Uzbekistan
}

\begin{abstract}
This article deals with the analysis and development perspectives of the use pumped storage power plants use to increase the reliability and regime controllability of electric power systems of the Republic of Uzbekistan.
\end{abstract}

\section{Introduction}

One of the main issues of increasing the reliability and operational controllability of electric power systems (EPS) is the issue of accumulation of generated energy.

Energy storage has been used in a wide variety of energy purposes, previously, it was used as a reserve power, which compensated the blackout disruption at the electricity transmission, and in the present time is used to solve a wide range of tasks, ranging from improving the overall reliability of the power system to the provision of system services on the market electricity. Recently, it has become clear that the effective development of the renewable energy use sources is impossible without energy storage, since the nature of its receipt from these sources is sharply variable [1-4].

Energy storage system can provide the advantages and flexibility for consumers, managers of energy companies and utilities, and can also participate in a number of market segments, especially in the electricity markets, acting as a direct supplier of energy for the EES, and to individual consumers [3, 4].

As you know, with the accurate unevenness of the load schedule, the presence of peaks and sharp decreases in the level of energy consumption create technical problems for energy producers related to the need to ensure compliance with the production and consumption of electricity, i.e. reduced electricity generation during periods of low consumption.

This leads to three groups of problems : firstly, the efficiency of using the installed capacity of power equipment is reduced, which is the most important factor affecting its payback; secondly, the frequent operation of power equipment in variable mode dramatically increases fuel consumption at thermal plants and leads to previously temporary wear of equipment; thirdly, the technical ability to reduce the power of generating equipment is often insufficient to compensate for the reduction in consumption, in this case, excess electric power is transferred to other regions [5 - 11].

To pass periods of nightly lows, power plants are forced to dump power. Furthermore, loss of increased fuel consumption and equipment due to uneven load, as well as loss of power transmission over long distances entail reducing economical profitability generating capacity.

In world practice operating large EPS solve uneven consumption of electricity is achieved either by creating special maneuvering power equipment (peak power plants, gas turbine power plant), or using the battery, consuming excess power during periods of general load reduction in EPS and outputs it to periods of increased consumption [1-9].

Numerous foreign studies prove that the use of maneuverable power plants operating in a variable load mode leads to a significant consumption of fuel, a decrease in the efficiency of using installed capacity, a decrease in the service life of equipment, and other negative consequences [4 - 9].

The most promising way to solve this problem is the use of pumped storage power plants (PSPP), which are both a highly maneuverable peak power source and a consumer-regulator [5-9, 12-15].

PSPPs are the main type of storage systems; currently, they account for $96 \%$ of the accumulated energy in the world [16]. Composition PSPP consists of hydropower installations, as values for generating power and pumping water into the upper reservoir, which is the hydraulic energy storage. Often the volume of the upper and lower reservoirs in a fixed time does not match, because the time of the turbine operating mode does not match the temporary pumping of the second mode.

World experience in PSPPs exploitation in various countries convincingly proves their technical efficiency to ensure the profitability of energy systems, manifested in the increase and reliability of power supply and power quality [9, 12-15]. Currently, in the world there are more

*Corresponding author: mukhammadiev_m@rambler.ru 
than 460 operating PSPP different layout with wide range installed capacity - from $100 \mathrm{M} \mathrm{W} \mathrm{3,000} \mathrm{MW}$ (PSPP Edison in the U.S.A and pressure of several tens of meters to 1,700 meters (PSPP Reyseek - Kraytsek in Austria), the total installed capacity of which exceeds $150 \mathrm{GW}$ [9, 15]. According to the IRENA agency projections is expected to increase power PSPPP to 325 GW in 2030 [17].

\section{Methods and models for the use of PSPPPs in the EPS of the Republic of Uzbekistan}

Studying the operation experience of the electric power industry of Uzbekistan and mill shows that one of the main issues of reliability improve of power supply is necessary to ensure range and dynamic regulations of power generating, which would fully meet the requirements of energy consumption. As is known, this problem is solved by selecting the optimum structure generating capacity, which provides stability and profitability of the EPS.

Coefficient irregularity ratio curve of power consumption (daily load curve) EPS of the republic is $\mathrm{K}_{\mathrm{nm}}=0,72-0,76$, which causes certain difficulties to the peak load coating and to a greater extent to the pass of the night at least to have accurate load curves.

This problem is typical for the thermal power plants (TPP) of the republic, which is planned to reconstruct inefficient power units to more modern and efficient. The compelled decrease in capacity at night time hours minimum taking into account necessity of performance of the schedule of load curve and maintenance of uniform work of power units becomes a serious problem for them. In addition, in connection with sharp increasing of load problems of quality maintenance of the electric power (maintenance of normal of frequency and voltage values) in the evening become aggravated.

Russia and other foreign countries EPS experience with predominance TPP, both and in Uzbekistan shows that the proportion of highly mobile units fraction $\mathrm{w}$ in at least $25 \%$ of the total installed power of the energy of the system $[9,14]$. Thus for optimum organization and reliable operation TPP proportion PSPPP (based on their ability to perform dual $\mathrm{p}$ e -regulation - both generation and load) should be $10-12 \%[9,10,14]$. Unfortunately, this parity in the republic power supply system is not observed yet.

Insufficient proportion of highly maneuverable hydroelectric power plants (HPP) and PSPP in the structure of generating power of EES of the Republic forces power regulation with thermal power plants. This leads to deterioration of power supply, in particular the voltage and frequency of the power system, since those are thermal power plants cannot quickly change the power. Frequent starts and stops of turbo units results over-expenditure the fuel, reduce the durability of thermal power equipment and increase the costs of maintenance, repair, deterioration of the ecological situation in TPP located areas [9].
By the data of Unitary Enterprise "Talimardjan TPP" in Uzbekistan in 2017, the total fuel consumption for starts and stops power blocks was $1601.000 \mathrm{~m}^{3}$, which corresponds to the loss of fuel at each start an average of $320.000 \mathrm{~m}^{3}$ natural gas.

According to the JSC "Uzbekenergo" in 2018, the value of the average specific fuel consumption was 354.6 g.c.f. $/ \mathrm{kW} \cdot \mathrm{h}$, and in the EPS countries where the proper regulation of capacities, and with use of PSPPP, this figure does not exceeds 330.0-340.0 g.c.f./kW·hour $[12,13]$.

The main cause of accelerated wear of heating equipment at his frequent and short stops is uneven temperature state various hours by the elements of the turbine, boiler and steam, leading to their cooling at different speeds, and about $25 \%$ of emergency stops power occurs due to damage in the course of their starting modes [8, 9, 10, 18$]$.

All the above-stated problems in the power system of the Republic indicate a need for the development of the construction of highly maneuverable power plants using renewable energy sources, primarily pumped storage power plants.

Currently, the Republic has adopted state programs for the construction of a number of small and mediumsized hydroelectric power stations [19]. However, it can solve only part of the problem, i.e., PSPP may cover only peak and booting providing vides the removal tension associated with the passage of the peak daily schedule by producing a cheap and clean energy. The other part of the problem, i.e. preventing failures generated loads can only be solved by construction PSPPP, which works on load curve failures in the pumping mode, providing a more favorable basis regime mode of TPP, and also promoting decrease in interstation overflows of energy.

In addition to the above advantages of PSPP may have a so-called fuel effect which is achieved due to the difference in fuel consumption during periods of energy storage and generation peak power. During periods of pumping mode, that correspond to minimal load curve, PSPPs consumes energy, which generated by basis power plants with the specific expense of conditional fuel $\mathrm{G}_{\mathrm{n}}=0.2$ to $0.27 \mathrm{~kg} /(\mathrm{kW} \cdot \mathrm{h})$. Then generation mode of PSPP replaces load thermal power plant installations in peak mode with the specific expense of conditional fuel $-\mathrm{G}_{\mathrm{g}}=0,5 \mathrm{~kg} /(\mathrm{kW} \cdot \mathrm{hr})$. If the efficiency PSPP take $\eta=0,70-0.75$, the specific fuel savings equal to 0.16 $0.187 \mathrm{~kg} /(\mathrm{kW} \cdot \mathrm{h})[6,10,12]$.

\section{Discussion and results}

As an example, we show how to efficiently use of PSPP in EES the Republic of Uzbekistan, using a daily schedule of electricity generation received from JSC "Uzbekenergo" for 23.07.2017 (Fig. 1). 


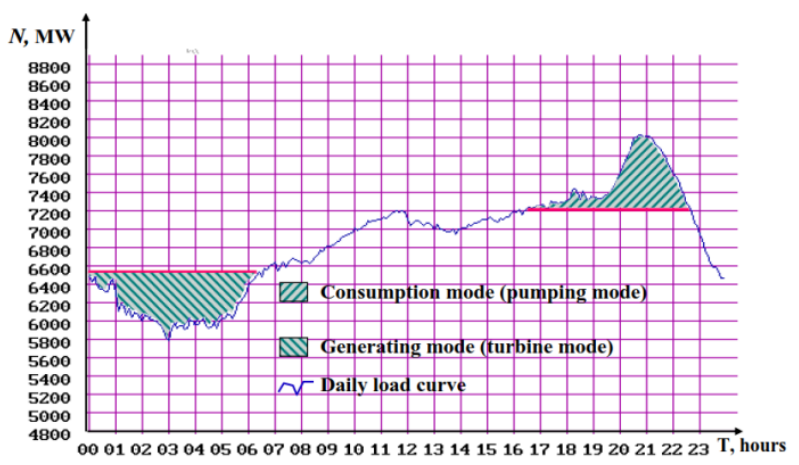

Fig. 1. Schedule of daily electricity generation EES of the Republic of Uzbekistan

It marked on the working zone of pumping stations of the PSPP power consumption regime in the minimum load and the working zone in the turbine mode of PSPP in the peak part of the curve. If such mode will adhere, the PSPPs in pumping mode will consume approximately 2,000 MW'hour electricity for 6 hours, and this power equivalent to volume of water will collect in the reservoirs. When taking efficiency PSPP 0.75, then the volume of water allows to generate 1,500 $\mathrm{MW}$. hour electrical energy during 6 hours in a peak part of the curve. It means, that only at the expense of fuel effect it is possible will save 240-280 t.c.f. per day. In this case, the coefficient of non-uniformity of the daily load schedule varies from $\mathrm{K}_{\mathrm{nm}}=0.72$ to $\mathrm{K}_{\mathrm{nm}}=0.91$.

The daily load profile EES Republic most tense in winter $\mathrm{n}$ e IRS. The peak load in December - January month ah is about $22-25 \%$ more than the average, but the maximum regulation capacity of HPP Republic for by covering of this load does not exceed $12 \%$ of the installed capacity of all power plants.

All this points to the need to intensify the use of hydropower and other alternative energy sources, the parallel improvement management of these resources on energy-saving background.

In our opinion, the main prerequisites for using PSPP in Uzbekistan are:

- increasing demand in maneuver power for covering daily load peaks and compensation its short-term variations;

- the use of cheap night electrical power in the failures of the daily load schedule;

- need to optimize the basic power plants;

- fuel economy in the power system by comparing with other variation peak power;

- providing a quick operational reserve;

- participation in the regulation of operational parameters in order to ensure standard quality of electrical power.

One characteristic feature of PSPP in abroad is that they are usually located energy centers in industrial and urban areas of the country or near to non maneuverable powerful source of electrical power [20]. Under these conditions, control of the current produced and consumed energy will be significantly effective and the power losses will be less [19].

As an example, we can cite the complexes "TPP - PS - PSPPP", geographically located in proximity to each other.
Pump stations (PS) water systems are large energy consumers, and often their work has seasonal character and depends on the accepted order of irrigation works on under the command areas to them. At present, 17-18\% of electric energy from the volume of the republican energy consumption is consumed by irrigation pumping stations [21].

Most of these pumping stations continuously work 810 months during the year in changing charge of water and less change head pressure. In the water management system of the republic, there are also PS of year-round operation, which, outside the irrigation time, serve to fill the reservoirs. Many of the PS, the servant of the melt during the growing season, are operated in full power 34 months a year (mostly in May - August), and in this connection their operating ratio of the installed power on time does not exceed 50-60\%.

In our opinion, in the current circumstances it would be appropriate to use the spare power of large PS to accumulate hydraulic energy by adapting their operation to the modes of operation of TPP, which are the source of power supply of pumping units.

As one of such examples of the possible use of PS, a diagram of the pumping station and PSPP is shown (Fig. 2.).

PS can work weekly, or even yearly regulation power load, but it needs more wide-ranging tasks and you are associated with an increase in additional volumes of reservoirs and equipments of PSPP. In this regard, the inclusion of the PS of water system into hydraulic energy storage is advantageously carried out to cover the daily load curve.

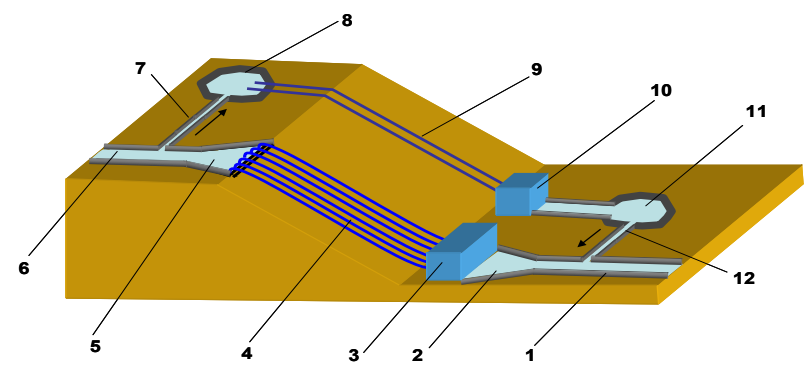

Fig. 2. PSPP position at the pumping station

1 - water supply channel; 2 - entrance bay; 3 - building of the pumping station; 4 - pressure pipelines; 5 - pressure head reservoir; 6 - outlet channel; 7 - feeding channel; 8 - upper reservoir; 9 - turbine pipelines; 10 - hydroelectric power station building; 11 - lower reservoir; 12 - water intake channel.

These PSPP have connection with high voltage power lines basic nodal distribution substations the consumer and large switchgear TPP. Related location PSPP allows:

- to carry out a normal operation, the energy system controller function characteristic for the PSPP in order to increase the reliability and quality of power supply; - in an emergency, due to the commissioning of the PSPP in the power supply structure of large energy consumers, address and emergency backup of generating capacity; 
- to compensate for the load that went out of service due to an accident in the turbine units of the TPP, while maintaining their rotating generating power .

As an example, we cite the option of using the PSPPPS-TPP system, based on the Talimardjan TPP and six pumping stations of the Karshi main channel.

Pumping stations on Karshi main channel are large energy consumers with an annual rate of 2.0 - 2.2 billion kilowatt-hours that equal $3,5-3,6 \%$ of the total production of energy in the republic. Placing PSPP near to current PS (in the vicinity of each of the six PS will settle the relevant PSPP), in our opinion, it is not only beneficial in terms of cost savings by eliminating the need to install pumps, and can improve operation Talimardjan TPP, which is a source of energy and is located near the PSPP. It can be illustrated the following example using the daily schedule power generation Talimardjon TPP shown in Fig. 3.

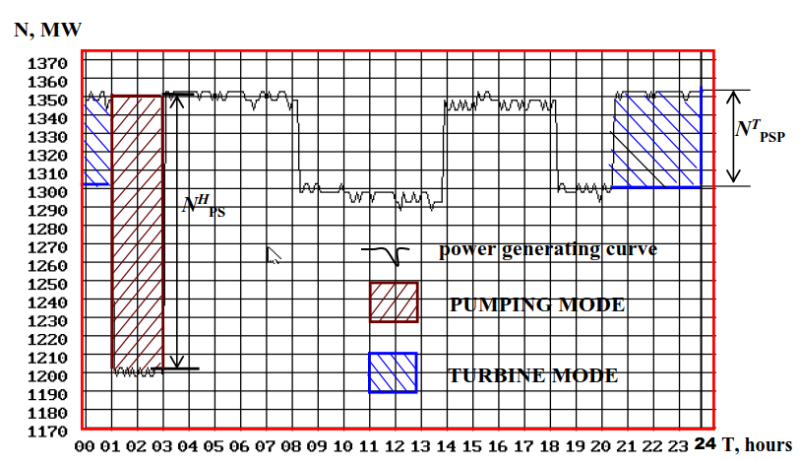

Fig. 3. Modes for PSPP daily schedule of power generation Talimardjan TPP

The decrease in energy production from $01^{00}$ to $03^{00}$ a.m. the power of one CCP-150 unit with a capacity of $150 \mathrm{MW}$ is switched off, as a result of which the power of the station dropped to $1200 \mathrm{MW}$. This failure to use a daily schedule for charging the upper reservoir, increasing electricity generation to 1350 MW (i.e., without shutting down the unit at TPP) due to power consumption pumping mode $150 \mathrm{MW}$. The upper reservoir will be filled by existing PS, by supplying water through a connection channel (Figure 2).

In the period from $20^{30}$ to $01^{00}$ the PSPP operates in turbine mode, supplying water from the upper reservoir to the lower one, while the power of the generating regime is about $52.5 \mathrm{MW}$ and the duration of operation is 4.5 hours. As a result of this, the operation mode of the state district power station is significantly improved, the unit shutdown is excluded, the unevenness coefficient of the daily schedule is changed, if this parameter had a value of $k=0,889$, then in the new mode it can have a value of $k=0,954$.

This PSPP option has the following indicators: 1. Power of PSPP on pumping mode $\mathrm{N}^{\mathrm{P}}=150 \mathrm{MW}$ and turbine mode $\mathrm{N}^{\mathrm{T}}=52,5 \mathrm{MW}$.

2. Working time: on pumping mode 2.0 hours and 4.5 hours on turbine mode.

3. The volume of water: $\mathrm{V}=700000 \mathrm{~m}^{3}$.

The calculation results showed the cost-effectiveness of the PSPP compared with TPPs of similar capacity with cost savings of $\$ 1,708$ thousand per year, a payback period of 5.09 years and a cost of $\$ 0.07 / \mathrm{kWh}$.

\section{Conclusion}

1. As the most perspective direction of achievement of reliability and regime controllability of Republic Uzbekistan EES use PSPP, which simultaneously are highly maneuver a source of peak power and the consumer-regulator in the minimum load is offered.

2. The results of the calculations to determine the economic efficiency of pumped storage systems - PS thermal power plant as an example Talimardjan TPP and six pumping stations Karshi main channel showed that economic effect of the substitution power of TPP, and also due to the fuel of the first effect and the provision of ancillary services does not output and so the scope of global indicators and pointing e $t$ to achieve a significant economic effect.

3. The stated material and the received results of this paper points to the need for deeper studies on the possible uses of the PSPP in the power system of the Republic of Uzbekistan, the development in the principles and methods of work to changing conditions, control modes of operation of the EPS in the normal and emergency situations.

Figures and tables, as originals of good quality and well contrasted, are to be in their final form, ready for reproduction, pasted in the appropriate place in the text. Try to ensure that the size of the text in your figures is approximately the same size as the main text (10 point). Try to ensure that lines are no thinner than 0.25 point.

\section{References}

1. Electricity storage and renewables: Costs and markets to 2030

http://www.irena.org/publications/2017/Oct/Electricit y-storage-and-renewables-costs-and-markets

2. Electric Power Research Institute: Electricity Energy Storage Technology Options. A White Paper Primer on Applications, Costs, and Benefits https://www.iea.org/publications/freepublications/pu blication/Technology RoadmapEnergystorage.pdf.

3. International Energy Agency: Technology Roadmap on Energy Storage, (2014)

https://www.iea.org/publications/freepublications/pu blication/Technology RoadmapEnergystorage.pdf

4. European commission directorate-general for energy. DG ENER Working Paper. The future role and challenges of Energy Storage

https://ec.europa.eu/energy/siTPP/ener/files/ energy storage.pdf

5. V.V. Elistratov. The use of renewable energy. 225 (2008)

6. Y.S.Vasiliev, G.A. Pretro. Pumped storage power plants. LPI. 76 (1984)

7. Electrical Energy Storage. IEC white paper; December 2011. 
http://www.iec.ch/whitepaper/pdf/iecWPenergystorage-LR-en.pdf

8. V.V. Zubarev Accumulating power plant and uses them as of a power systems. issue 4, 34-38 (1986)

9. V.Y. Sinyugin, V.I. Magruk, Rodionov V.G. Hydroaccumulative power plants in modern electric power industry. ENAS, 352 (2008)

10. L.B. Scheinman, Accumulating power plants. Energy, 184 (1978)

11. Energy storage - packing some power. The economist.

$\mathrm{http}: / / \mathrm{www}$. economist.com/node/21548495?frsc = $\mathrm{dg} \% 7 \mathrm{Ca}$

12. C.J. Yang, Pumped hydroelectric storage: Technical report, (2011)

https://wiki.opensourceecology.org/images/5/5d/Phs. pdf

13. Paul Denholm, Erik Ela, Brendan Kirby and Michael Milligan. The Role of Energy Storage with Renewable Electricity Generation. NREL / TP-6A247187 (January 2010)

14. Brandi A. Antal. Pumped Storage Hydropower: A Technical Review. 84 (2014)
15. Istvàn Tàczi. Pumped Storage Hydroelectric Power Plants: Issues and Applications, Energy Regulators Regional Association. Budapest, Hungary, 11 (2016)

16. Renewables 2017 Global Status Report. http://www.ren21.net/wpcontent/uploads/2017/06/178399_GSR_2017_Full_Report_0621_Opt.pdf

17. Renewable nergy sources and storage of electrical energy (June 2015)

https://www.researchgate.net/publication/314154863 Renewables and Electricity_Storage_A_technology_Roadmap

18. V.A. Zubakin is necessary to develop highly maneuverable powerful about STI // Energy market. 34-42, 9 (2004)

19. M.M. Muhammadiev, B.U. Urishev Hydroaccumulative power plants. Fan va texnologiya, 212 (2018)

20. C. Yang and R. B. Jackson. Renew. Sustain. Energy Rev., vol. 15, no. 1, 839-844, (Jan. 2011)

21. M.M. Muhammadiev, B.U. Urishev, Energy efficient technologies in the operation of pumping stations. 115 (2012) 